\title{
LA ORDNUNGSPOLITIK DE LA NUEVA ECONOMÍA INSTITUCIONAL*
}

\author{
Nieves San Emeterio Martin ${ }^{\mathrm{a}}$ \\ Victoria Romero Ojeda \\ Giuseppina Di Capua
}

"DOI: https://doi.org/10.18601/01245996.v23n45.06 Recepción: 21-012019, modificación final: 14-04-2021, aceptación: 02-06-2021. Sugerencia de citación: San Emeterio, M. N., Romero, O. V. y Di Capua, G. (2021). La Ordnungspolitik de la nueva economía institucional. Revista de Economía Institucional, 23(45), 109-135.

a Doctora en Economía. Departamento de Economía Aplicada I, Historia e Instituciones Económicas y Filosofía Moral. Universidad Rey Juan Carlos de Madrid, [nieves.sanemeterio@urjc.es], [https://orcid.org/0000-00017579-1802].

b Doctora en Economía. Universidad Rey Juan Carlos de Madrid, [victoria. romero.ojeda@urjc.es], [https://orcid.org/0000-0001-9097-915X].

c Doctora en Economía. Departamento de Economía Aplicada I, Historia e Instituciones Económicas y Filosofía Moral. Universidad Rey Juan Carlos de Madrid, [giuseppina.dicapua@urjc.es], [https://orcid.org/0000-00031189-8584]. 


\section{La Ordnungspolitik de la nueva economía institucional}

Resumen Aunque la escuela historica alemana y el institucionalismo americano son los principales los antecedentes de la nueva economia institucional, otras escuelas -como el ordoliberalismo aleman- tambien ejercieron una posible influencia en el neoinstitucionalismo Este articulo explora sus puntos comunes, con base en la obrade Walter Eucken, cuya propuesta de politica economica coincide, aunque con ciertos matices, con la de Coase, North y Williamson, fundadores de la nueva economía institucional, en la necesidad de un Estado que establezca un orden basado en una estructura de normas e instituciones que permita el correcto funcionamiento del mercado competitivo, en el caracter multidisciplinario de sus estudios, en el rechazo de los monopolios y grupos de interes que controlan el Estado y en el papel de la empresa como organismo planificador que rivaliza con el Estado.

Palabras clave: Estado, nueva economia institucional, escuela de Friburgo, Ordnungspolitik, Walter Eucken; JEL: E02, E52, E70.

\section{The Ordnungspolitik of the new institutional economics}

Abstract Although the German historical school and American institutionalism are the main antecedents of the new institutional economics, other schools - such as German Ordoliberalism- also exerted a possible influence in the new institutionalism. This article explores the common points between the two schools, based on the work of Walter Eucken, whose economic policy proposal coincides, although with certain nuances, with that of the founders of the NEI -Coase, North and Williamson-in the need for a State that establishes an order based on a structure of rules and institutions that allows the proper functioning of the competitive market, as well as the multidisciplinary nature of its studies, the rejection of monopolies and interest groups that control the State and the role of the firm as a planning body that rivals the State.

Keywords: State, New Institutional Economics, Freiburg School, Ordnungspolitik, Walter Eucken; JEL: E02, E52, E70

\section{O Ordnungspolitik da Nova Economia Institucional}

Resumo Embora a escola histórica alemã e o institucionalismo americano sejam os principais antecedentes da nova economia institucional, outras escolas - como o ordoliberalismo alemão - também exerceram uma possível influência no neoinstitucionalismo. Este artigo explora seus pontos comuns, com base na obra de Walter Eucken, cuja proposta de política econômica coincide, embora com certas nuances, com a de Coase, North e Williamson, fundadores da nova economia institucional, na necessidade de um Estado que estabeleça uma ordem a partir de um estrutura de normas e instituições que permite o bom funcionamento do mercado competitivo, no caráter multidisciplinar de seus estudos, na rejeição de monopólios e grupos de interesse que controlam o Estado e no papel da empresa como órgão de planejamento que rivaliza com a Condição .

Palavras-chave: Estado, nova economia institucional, escola de Freiburg, Ordnungspolitik, Walter Eucken; JEL: E02, E52, E70 
$\mathrm{L}$

a transformación económica y social de Europa en los años siguientes a la Segunda Guerra Mundial y el derrumbe del nazismo fueron caldo de cultivo para las ideas que cuestionaban el orden político, económico y social vigente, y se convirtieron en leit motiv de economistas de la época como Walter Eucken en Alemania, William Beveridge en Inglaterra o Karl Polanyi en Estados Unidos.

El reconocimiento de la profunda crisis del orden económico liberal y el cuestionamiento de la economía capitalista llevaron a proponer soluciones alternativas o respuestas político-económicas intermedias alejadas del socialismo y el comunismo, en las que el Estado fuese el principal ejecutor, regulando u ordenando el sistema.

En Alemania, la propuesta de una "tercera vía"1 -opuesta al totalitarismo centralista del comunismo y del nacionalsocialismo, que amenazaba las libertades individuales y la prosperidad económica, así como la gestión estatal del mercado en el marco del laissez-faire- fue impulsada por Walter Eucken, la figura más representativa de la escuela ordoliberal de Friburgo ${ }^{2}$. Esta tercera vía defendía un capitalismo ordenado y conducido por el Estado, que debe mantener el orden económico mediante un estricto control regulatorio. A diferencia de los marxistas, para los ordoliberales el problema no era la naturaleza del capital sino la capacidad o incapacidad del gobierno para regular el nivel de tensión social. No criticaban el capitalismo sino los elementos no controlados o no regulados que lo distorsionan, que al dejarse al libre juego del mercado crean efectos perversos.

La corriente ordoliberal solo tuvo un "reinado efímero" en Alemania y fuera de sus fronteras, y llegó a ser una gran olvidada cuya influencia, aparte de sus similitudes -señaladas por diversos autores- con el neoliberalismo alemán, la economía social de mercado, la escuela de la elección pública y el constitucionalismo de James Buchanan, apenas ha sido reconocida; especialmente en el caso de la nueva economía institucional $(\mathrm{NEI})^{3}$.

${ }^{1}$ Dritte Weg, término acuñado por Walter Eucken.

${ }^{2} \mathrm{Su}$ denominación proviene de la publicación Ordnung der Wirtschaft, dirigida por el economista Walter Eucken (1891-1950) y el jurista Franz Böhm (1895-1977), que continuó el proyecto que ellos iniciaron en 1936 junto a Hans Großmann (1894-1944), Die Ordnung der Wirtschaft als Geschichtliche Aufgabe und rechtsschöpferische Leistung, que buscaba devolver al Derecho Político y a la Economía Política el lugar que les correspondía, después de ser relegadas por el historicismo. A ellos se unió Leonhard Miksch (1901-1950).

3 Pese a los paralelismos entre la Ordnungspolitik de Eucken y el constitucionalismo americano, Buchanan no le atribuye influencia alguna en sus planteamientos, y señala que la escuela sueca y Knut Wicksell fueron su principal inspiración. No obstante, Vanberg (2006) sostiene que así no haya 
Este "olvido" puede deberse, entre otras razones, a su oposición al método más empirista y a la influencia historicista, que la alejan de la corriente neoclásica y le valieron duras críticas, especialmente en Reino Unido, donde Hutchison recopiló referencias a la obra de Eucken en su país y en Estados Unidos, señaló que "la mayor parte de los comentarios en Gran Bretaña y Estados Unidos tienden a ser recelosos, de desaprobación, derrotistas o francamente condenatorios" (Hutchison, 1979 , p. 435), y puso como ejemplo un comentario publicado en The Times Literary Supplement, que concluía que nadie en Inglaterra tenía algo que aprender de Eucken y de su libro Cuestiones fundamentales de la economía política, publicado en inglés en 1950 (Richter, 2010) ${ }^{4}$.

La Gran Recesión de la década pasada desempolvó muchos planteamientos de la escuela de Friburgo sobre un orden económico mejor establecido, cuyo garante sea el Estado, los cuales se han empezado a considerar como una opción cada vez más plausible para reorientar la economía y muy próxima al neoinstitucionalismo.

Este artículo examina los planteamientos teóricos de la corriente ordoliberal y sostiene que su propuesta de política económica coincide en aspectos básicos con la de los neoinstitucionalistas, como la necesidad de un Estado que cree normas e instituciones que hagan posible el buen funcionamiento del mercado competitivo (Wettbewerbsordnung) y garantice el bienestar social, si bien ambas escuelas difieren en cuanto a la capacidad del Estado, más restringida en opinión de la NEI.

Para comparar los fundamentos teóricos de ambas corrientes se contrasta el cuerpo teórico del ordoliberalismo -expuesto por Eucken en sus principales obras, Cuestiones fundamentales de la economía política, publicado en su primera edición alemana en 1939; y Principios de politica económica, obra póstuma de 1952- con los aportes Ronald Coase, Douglas North y Oliver Williamson en cuatro pilares fundamentales:

1. E1 concepto de institución y el papel del Estado,

2. La problemática de los monopolios,

3. La multidisciplienariedad,

4. El papel de la empresa como institución.

Consideramos a Eucken, y no a otros autores de la escuela, porque este fue su impulsor y máximo exponente, y sus escritos suscitaron gran una conexión directa entre el ordoliberalismo y las ideas de Buchanan, Economía politica para una sociedad libre de Henry Simons sería un vínculo indirecto, pues Eucken la menciona como una de las obras más afines a sus ideas y Buchanan reconoce la fuerte influencia de Simons.

${ }^{4}$ La edición alemana data de diez años antes y la española de 1947. 
interés; como muestra su temprana traducción al castellano. Cuestiones fundamentales de la economía política se publicó en alemán en 1939 y en 1947 apareció en España su primera edición en la colección Biblioteca de la Ciencia Económica de Revista de Occidente. Eucken estuvo de visita en España en 1949, poco antes de su fallecimiento en $1950^{5}$.

Cabría preguntar si la obra de Eucken tuvo influencia directa en algunos neo-institucionalistas, como influyó en algunos economistas españoles de la época. Si consideramos los tres premios Nobel cuya obra cotejamos con la de Eucken, por edad solo Coase pudo conocerlo. Es posible que se hayan conocido, pues en 1950, cuando Eucken fue a la LSE a dar la conferencia truncada por su muerte repentina, Coase era profesor allí. Aunque por lo que sabemos de la estancia de Coase en la LSE, no parece que Eucken le influyera en lo más mínimo. En sus Ensayos sobre economía y economistas (2009), no alude a Eucken. Ni tampoco al ordoliberalismo cuando rememora su estancia en la LSE en los años treinta ${ }^{6}$. Los otros dos autores, North y Williamson (de una generación más joven que Coase o Eucken), tampoco aluden a Eucken como inspirador y en sus trabajos no hay referencias que indiquen que conocieran sus ideas; lo que demuestra la escasa repercusión de las ideas ordoliberales en el ámbito anglosajón. Como señaló Hutchison, las ideas ordoliberales fueron mal recibidas por los economistas británicos y norteamericanos (Hutchison, 1979, pp. 434-437). Si bien en Alemania no fueron rechazadas, sí fueron olvidadas. En los años cincuenta, los jóvenes economistas alemanes fueron perdiendo interés por la Escuela de Friburgo eclipsada por la Teoría general de Keynes y la teoría neoclásica de Hicks o Samuelson. En la década siguiente la influencia de esta escuela se desvaneció por completo en su propia tierra (Richter, 2000, pp. 6-7).

En las páginas siguientes, intentamos establecer los nexos entre dos escuelas y entre autores que no se conocieron, pero que estudiaron

5 Velarde (1998) recuerda esta visita, en la que dejó copia de "Política económica del laissez-faire, economía planificada, y orden de la competencia”, preludio a su obra póstuma. La traducción que utilizamos y que cita el profesor Velarde fue publicada en la Revista Arbor entre enero y marzo de 1950. La comparación de las publicaciones en alemán y castellano indica que los conceptos, planteamientos y disposición del artículo mencionado coinciden plenamente con los de esa obra. Muestras del renovado interés por este autor son la traducción de los Principios en formato completo por la Fundación ICO y el artículo de Santiago García (2018).

${ }^{6}$ El único vínculo que se puede encontrar es que Coase (2009, p. 229) copiaba los apuntes en la clase de Lionel Robbins de Vera Smith, la esposa der Friedich Lutz, un economista que fue asistente de Eucken en Friburgo a comienzo de los años treinta. 
el sistema económico desde perspectivas muy similares. Sostenemos que para escuelas la economía teórica había abandonado el marco institucional como objeto de estudio, aunque era fundamental para garantizar el correcto funcionamiento de la actividad económica. La primera sección presenta el estado de la cuestión considerando las referencias más relevantes sobre el tema, que no son muy numerosas; de ahí la novedad del enfoque. Luego se señalan los vínculos comunes entre ambas escuelas haciendo un recorrido por el terreno conceptual y sus objetivos analíticos con base en los cuatro pilares antes mencionados. Por último, se hace una reflexión sobre la clara cercanía entre el ordoliberalismo y la NEI.

\section{ESTADO DE LA CUESTIÓN}

Entre los antecedentes históricos de la NEI se suelen considerar la escuela histórica alemana, el institucionalismo americano y la escuela austriaca; pero es difícil encontrar un vínculo común entre esas corrientes y la NEI con respecto al papel del Estado. Las dos primeras, más intervencionistas, recomiendan la participación pública para proteger sectores estratégicos, así se alejan de la NEI, mucho más liberal, que no comparte el talante libertario austriaco.

Aunque es bien conocida la batalla entre los historicistas alemanes y la escuela austriaca en la disputa sobre el método (Methodenstreit); en ese contexto, la preocupación de los ordoliberales por las implicaciones políticas de la concentración del poder económico y el papel del Estado en la economía constituye una posición intermedia entre historicistas y austriacos (Richter, 2010, p. 2), que coincide la NEI en el esfuerzo por entender el papel de las instituciones y su relación con el comportamiento humano.

Aunque apenas se encuentran estudios amplios sobre el tema, se ha ido reconociendo progresivamente la influencia ordo en la formación de la corriente neoliberal de los años treinta. Hasta hace poco eran escasos los trabajos que indagaban su papel como antecedente teórico de la NEI pese a que, como señala Ptak, es "una doctrina neoinstitucionalista embrionaria avant la lettre" (2009, p. 126).

Entre esos trabajos pioneros cabe señalar los de Hutchison (1979), Schmidtchen (1984) y los más recientes: Furubotn y Richter (1997) y Richter (2000).

El artículo de Hutchison es especialmente relevante porque su autor tradujo varias obras de Eucken al inglés, incluida The foundations of economics. En su artículo, Hutchison examina la repercusión de las 
ideas de Eucken en Gran Bretaña y Estados Unidos, y muestra que los hechos y las ideas no siguieron caminos idénticos. Mientras que en los años cincuenta y sesenta era indiscutible el milagro económico de Alemania Occidental, en la cuna de la economía, las recomendaciones políticas ordoliberales eran denostadas, aunque inspiraron el supuesto milagro.

Gráfica 1

Influencias teóricas del ordoliberalismo

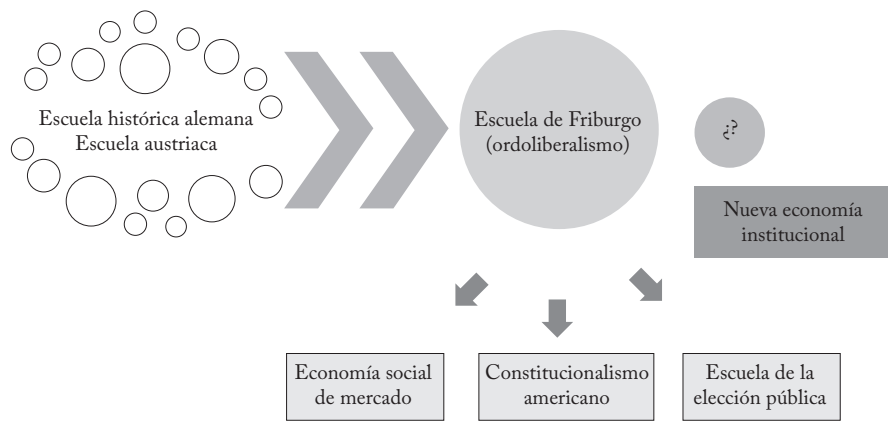

Fuente: elaboración propia.

Schmidtchen (1984) señala los principales aportes de Eucken como representante de la Ordnungspolitik, en especial sus principios constituyentes, y los relaciona con aspectos de la economía institucional como la teoría de los derechos de propiedad, la interdependencia del sistema económico y las ideas de Coase sobre estructuras institucionales alternativas.

Furubotn y Richter examinan en detalle el tratamiento de las instituciones y los conceptos básicos de la NEI. Aunque no hacen muchas alusiones a la escuela de Friburgo, en las pocas ocasiones que la mencionan señalan sus nexos teóricos con la NEI, más en concreto con la tesis de Walter Eucken. Por su parte, Richter contextualiza las corrientes de pensamiento que han influido en el institucionalismo alemán desde la década de 1950, entre ellas la NEI, y hace numerosas referencias a fuentes actuales sobre el tema. Esa primera toma de contacto lo puso sobre la pista de un posible vínculo entre ambas corrientes, que profundizó en su trabajo de 2010.

Además, como ya se mencionó, la Gran Recesión llevó al resurgimiento de la concepción ordoliberal y a indagar sus posibles nexos con la NEI, como señalan Schnyder y Siems:

Los conceptos ordoliberales no son un fenómeno aislado, sino que están relacionados con las ideas de la economía institucional bajo diferentes 
nombres. Tales perspectivas 'ordoinstitucionales' han ganado presencia en el contexto de la crisis financiera actual, ya que parecen atenuar los enfoques extremos del liberalismo de mercado, mientras que continúan acomodando las ideas ampliamente neoliberales, anti-keynesianas y antisocialistas (2013, p. 250).

Estos autores recuperan la visión ordoliberal como una "tercera vía" alternativa a los acontecimientos desencadenados desde 2008, cuyo principal responsable es la política de laissez-faire; y contrastan las medidas adoptadas durante la crisis financiera con los fundamentos teóricos de la escuela. Hay quienes ha ido más allá, vislumbrando incluso un influjo ordoliberal en la política alemana durante la crisis de la deuda soberana de la zona euro (Dullien y Guérot, 2012).

Cesarotto y Stirati reconstruyen los paralelismos entre las medidas económicas adoptadas en la Alemania de la segunda posguerra y las adoptadas ante la crisis de 2008, e identifican una clara influencia ordoliberal en el neoinstitucionalismo $(2011,18)$.

Entre los trabajos que tratan con más detalle la influencia del ordoliberalismo en la NEI, más centrados en los entresijos teóricos y alejados de la Gran Recesión los más destacables son los de Vatiero (2010), Richter (2010) y Sally (2012).

Rudolf Richter es uno de los principales referentes por su dedicado estudio del vínculo entre el aporte ordoliberal y los planteamientos de la NEI; pese a sus diferencias, "los dos enfoques tienen un punto de interés común: el marco institucional de la vida económica”, y añade: "Por esa razón debe ser del interés de los neoinstitucionalistas analizar de cerca la Ordnungstheorie alemana" (2010, pp. 1-2).

Vatiero se opone a considerar el ordoliberalismo como una opción intermedia entre el capitalismo y el socialismo, sostiene que es "una forma diferente de liberalismo" (2010, p. 706) y propone reconsiderar en clave institucionalista algunos de sus principales planteamientos sobre los problemas del sistema de mercado. Con estas premisas establece los objetivos de su trabajo: replantear en clave institucionalista el implante teórico del ordoliberalismo, en particular desde la perspectiva del Institucionalismo de Thorstein Veblen y John Commons; pues como afirma: "El viejo institucionalismo y el ordoliberalismo pueden considerarse entre los más precoces precursores del moderno neo-institucionalismo, del análisis económico del Derecho y de la economía constitucionalista" (ibíd., p. 691). Pero Vatiero parece olvidar que el neo-institucionalismo comparte el núcleo duro neoclásico, y así se aleja de las posiciones heterodoxas de estas dos corrientes precursoras. 
En sus conclusiones, Razeen Sally (2012) reconoce la existencia de puntos de contacto entre el ordoliberalismo, por un lado, y la nueva economía política de la elección racional, la economía constitucional y la NEI, por el otro.

Otros autores identifican los aportes de la escuela de Friburgo en el contexto liberal de mediados de los años treinta, en el marco de la Mont Pelerin Society ${ }^{7}$. Aunque se debe señalar que antes de su fundación, la presencia de autores ordoliberales como Wilhelm Röpke o Alexander Rüstow en círculos neoliberales como el Coloquio Walter Lippman, celebrado en París en agosto de 1938, puso de manifiesto su interés por contribuir a establecer un nuevo liberalismo alejado del laissez-faire. En ese sentido, el ordoliberalismo no es en esencia muy diferente de otras vertientes neoliberales (Ptak, 2009), si bien la idea de un Estado fuerte se extiende en toda su tradición e intenta ir más allá para corregir las deficiencias del liberalismo tradicional.

Este escrito es parte del resurgimiento de las ideas ordoliberales, veladamente presentes en la política económica de la última década. Encuentra una estrecha interrelación entre la NEI y la corriente ordo, pero da un paso más, pues no solo la conecta con los principios básicos establecidos por Eucken sino con el conjunto de aportes contenidos en su obra. Pretende entonces dar una visión más completa del ordoliberalismo como antecedente de la NEI, es especial sobre el papel del Estado en la economía. Un Estado fuerte, independiente y legalmente determinante, cuyo poder discrecional no altera los procesos que conforman el sistema de mercado.

\section{EL INFLUJO ORDOLIBERAL EN LA NEI}

E1 sustrato teórico de la escuela ordoliberal está unido inevitablemente a la obra de Walter Eucken pues, como señalan Van Sutum et al. citando a Müller: Sus escritos "sin duda destacan como los más comprensibles y, desde el punto de vista económico, constituyen las bases mejor fundadas del pensamiento ordoliberal" (2011, p. 5).

Esas bases se construyen con un enfoque sistémico y sobre dos pilares: la Ordnungstheorie y la Ordnungspolitik. En palabras de Eucken:

es posible dominar el problema principal del orden político-económico de la actualidad en esta forma: la consecución de ciertos principios de la actividad humana es la primera tarea, y su aplicación la segunda, ta-

${ }^{7}$ Fundada en 1947, tras el llamado de Friedrich von Hayek, la Mont Pelerin Society se creó como un grupo de pensadores que buscaban intercambiar ideas sobre el presente y el futuro del liberalismo, en su sentido clásico, la Europa de posguerra. Ver, p. ej., Mirowski y Plehwe (2009). 
rea esta que varía incesantemente adoptando formas distintas (Eucken, 1950c, p. 333).

La Ordnungstheorie es el análisis de los fenómenos económicos desde una perspectiva propia que reconoce la importancia y la influencia del devenir histórico y de los fenómenos no económicos. Y la Ordnungspolitik es el conjunto de acciones que favorecen el funcionamiento económico, es decir, la política que debe seguir el Estado, entendida no como intervención en el proceso económico, sino como elemento que lo define lo configura. Su objetivo primordial es mejorar el marco normativo, de modo que los resultados del proceso económico sean los socialmente deseables sin su intervención directa, como ocurría en los regímenes de economía planificada.

Por su parte, la contribución teórica de la NEI a finales del siglo XX suscitó el retorno de la prioridad analítica de las instituciones, cuya importancia se consolidó con la concesión del Premio Nobel Ronald Coase en 1991, Douglas North en 1993 y Oliver Williamson en $2009^{8}$.

Sus aportes se centran en tres ideas fundamentales en las que se basan sus obras sobre el marco y el cambio institucional: el concepto de "costos de transacción" de Coase en el marco del mercado, la empresa y la esfera pública; la concepción de instituciones como "reglas del juego" de North y la incorporación una teoría del Estado en el análisis económico; y el análisis de la gobernanza económica y de los límites de la empresa de Williamson.

Gráfica 2

Vínculos conceptuales entre la NEI y el ordoliberalismo

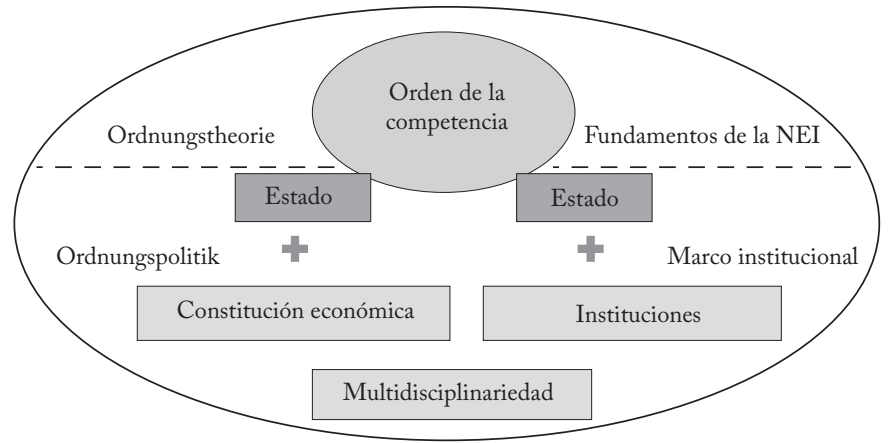

Fuente: elaboración propia.

${ }^{8}$ Debemos mencionar, además a Elinor Ostrom, quien recibió el Nobel en 2009 por su desarrollo de la NEI en el campo de la Economía de los Recursos Naturales. 
La NEI se origina en el marco neoclásico (individualismo metodológico, racionalidad individual y comportamiento maximizador), pero cuestiona su visión de un mundo perfecto en el que todo funciona bien y sin costo, y difiere en cuatro aspectos básicos: racionalidad, empresa, mercado y Estado como garante de la propiedad individual ${ }^{9}$.

La hipótesis de partida de este escrito es que existen importantes y evidentes puntos en común entre la Ordnungspolitik y los pilares fundamentales de la NEI. Hipótesis que intentamos corroborar analizando en paralelo los fundamentos teóricos de ambas corrientes para identificar sus puntos de encuentro y desencuentro.

\section{EL CONCEPTO DE “INSTITUCIÓN”Y EL PAPEL DEL ESTADO}

La Ordnungstheorie considera que los hechos económicos que acontecen día a día están estrechamente relacionados y constituyen un orden económico único o Wirtschaftsordnung (Eucken, 1947, p. 15). E1 orden económico resolvería una de los principales interrogantes de la economía, cómo dirigir el proceso económico (Lenkungsproblem), pues "el que dirige una formación económica actúa siempre con base en un plan económico" (ibíd., p. 114). Para Eucken, la evidencia histórica demostraba que este problema solo se había intentado resolver con dos modelos o sistemas económicos: el sistema planificado y el orden de mercado; las dos únicas evidencias "en la realidad económica del presente y del pasado” (ibíd., p. 115).

De la comprensión de los órdenes económicos existentes y de la crítica a las políticas económicas de la primera mitad del siglo, a la que Eucken llamó "era de los fracasos", surge la Ordnungspolitik, cuya "tarea central [...] en la economía industrial es formular las condiciones con arreglo a las cuales puedan desarrollarse órdenes económicos capaces de funcionar y dignos de los hombres" (Eucken, 1950 b, p. 184). Es decir, configurar un marco institucional tal y como lo definiría Douglas North años más tarde. Un marco institucional que debía ser diseñado por el Estado a través de la Ordnungspolitik para resolver el Lenkungsproblem, el cual era esencial para conseguir un orden económico consistente.

El diseño del marco institucional se llevaría a cabo mediante una "constitución económica", su elemento director, el garante de su unidad y su hilo conductor; es decir, debía ser un marco formal, legal e institucional, que, junto con las tradiciones y convenciones de las instituciones informales, configurara el orden económico.

${ }^{9}$ Sobre los principios y el desarrollo de la NEI, ver San Emeterio (2006). 
Igual que en el Estado de Derecho, el orden de la competencia debe crear un marco en el que la libre actividad de los individuos sea limitada por la esfera de libertad de los demás, con lo que se consigue el equilibrio entre los campos de libertad de los distintos individuos. En realidad, el deseo del orden de la competencia está íntimamente ligado al deseo de libertad (Eucken, 1950c, p. 330).

Así, la "constitución económica" se define como "la decisión total sobre el orden de la vida económica de una comunidad” (Eucken, 1947, p. 79) en la que el orden económico de la competencia es su razón de ser y cuyo contenido mínimo delimita Eucken:

E1 principio fundamental no solo exige evitar ciertos actos político-económicos, como las subvenciones oficiales, la formación de monopolios estatales obligatorios, el control general de precios, las prohibiciones de importaciones, etc. Tampoco basta prohibir, por ejemplo, los cárteles. E1 principio no es preferentemente negativo, sino que es necesaria una política constitucional económica positiva que aspire a desarrollar la forma de mercado de la competencia perfecta, cumpliendo así el principio fundamental (Eucken, 1950c, p. 336).

Pero este orden de la competencia conformado en torno a las directrices de la constitución económica requiere un diseñador y garante: el Estado. Un Estado concebido desde un punto de vista funcional, que debe formar parte del orden económico y garantizarlo, a través de la constitución económica, erigiéndose como "guardián del orden competitivo" (Hüter der Wettbewerbsordnung), (Vanberg, 2004); pero que en ningún caso intervendría en el proceso económico.

el Estado ha de influir en el marco institucional y en el orden dentro del cual se desarrolla la actividad económica, así como ha de fijar las condiciones en que se desenvuelve un orden económico capaz de funcionar y digno de los humanos. Pero no ha de dirigir por sí el proceso económico [...] Planificación estatal de las formas, sí; planificación estatal y dirección del proceso económico, no (Eucken, 1950c, p. 337).

Así pues, el diseño del orden económico o constitución económica constituye la razón de ser de la Ordnungspolitik emanada del Estado y basada en una serie de "principios constituyentes" y "principios reguladores". Los primeros se refieren a la construcción del orden de la competencia o de mercado (constitución económica) cuyo objetivo primordial habría de ser la creación de un mecanismo de precios viable, mientras que los segundos tratarían de mantener su capacidad funcional (ibíd., p. 334) ${ }^{10}$.

10 Tales principios se enumeran y explican en Grundsätze der Wirtschaftspolitik (Principios de politica económica), la obra póstuma de Eucken publicada en 1952. 
Cuadro 1

Principios constituyentes y reguladores del orden de la competencia

Principios constituyentes Principios reguladores

\begin{tabular}{ll}
\hline Estabilidad monetaria & Inexistencia de monopolios \\
Propiedad privada & Redistribución de ingresos y propiedad \\
Libertad de contratación & Salarios mínimos (en recesión) \\
Apertura de los mercados & Equidad de costos individuales y sociales
\end{tabular}

Responsabilidad social

Estabilidad de la política económica

Fuente: elaboración propia.

Así, a través de la política económica, el Estado es el encargado de aunar el bienestar y el interés común con los intereses particulares, evitando las tensiones recíprocas y favoreciendo el desarrollo de la economía de mercado. Un enfoque heredado-la teoría del laissez-faire, como señala Eucken:

E1 Estado creó precisamente en esta época un fuerte derecho de propiedad, de contratación, de sociedades, de patentes, etc., etc. Cada empresa y cada economía de consumo se movían cotidianamente en el marco de normas jurídicas impuestas por el Estado, dentro de las cuales compraban, vendían, tomaban a crédito o realizaban cualquier otro acto económico. ¿Cómo, entonces, se pudo hablar de una economía libre de la intervención del Estado? (1950b, p. 179).

Aunque el funcionamiento de la economía se dejara al libre albedrío de los agentes económicos, los cimientos institucionales de la economía serían determinados por el Estado. No obstante, el planteamiento de Eucken va más allá y es más contundente, pues da mayor protagonismo al Estado.

Para identificar las posibles convergencias con la NEI en este primer aspecto recurrimos a sus autores más representativos, cuyos aportes están contenidos en trabajos que consolidaron el reconocimiento, en la ciencia económica, de las instituciones y de la relación causal entre su papel y el crecimiento económico.

Hay similitudes con la obra de North en tres aspectos: la definición de institución, el papel del Estado y la visión dinámica del funcionamiento económico. Para North las instituciones, como "reglas del juego", constituyen "la estructura de incentivos de una sociedad y, en consecuencia, las instituciones políticas y económicas son los determinantes subyacentes de los resultados económicos"(North, 1994a, p. 764)"11. Esta concepción rememora el “orden económico" de Eucken.

11 Este artículo retoma su conferencia del 9 de diciembre de 1993 en el acto de entrega del Premio Nobel de Economía. 
E1 Estado es crucial tanto para North como para Eucken. North considera que hay instituciones ineficientes, que se deben estudiar las instituciones políticas y que se requiere una teoría del Estado, el cual define y hace respetar los derechos de propiedad, y establece el sistema de incentivos: "En última instancia, el Estado, que es responsable de la eficiencia de dicha estructura, es el causante del crecimiento, el estancamiento o el declive económico" (North, 1994b, pp. 33-34). Igual que para Eucken, los Estados no se limitan a la distribución. "Se ocupan de las normas subyacentes que forman la estructura de incentivos de una economía-derechos de propiedad, contrataciones y compromisos creíbles". (North, 1990b, pp. 356-357). Crearían la "Constitución económica" de Eucken.

Por último, North adopta una concepción dinámica del funcionamiento económico. Según él, no se puede entender la función de las instituciones si no consideramos antes su sujeción/propensión al cambio (1990a, pp. 18-19). El concepto de cambio institucional que propone North evoca el problema de la "gran antinomia" de Eucken y la naturaleza histórico-individual de la vida económica. Una naturaleza cambiante que lleva a que la economía muestre un "estilo total variante y carezca de toda uniformidad" (Eucken, 1947, p. 37), ya que "El ritmo al que los Estados modifican sus instituciones, sus ordenamientos del mercado y del trabajo, sus sistemas monetarios, etc., se ha acelerado extraordinariamente" (ibíd., p. 36). Por ello, concluye que el conocimiento científico de la economía real, la razón de ser de la Economía, "estará cumplido cuando se contesten dos preguntas para cada país y cada época: la pregunta sobre la estructura del orden económico y la pregunta sobre las relaciones del proceso económico que tiene lugar dentro de estos órdenes" (ibíd., p. 227).

La conexión entre Eucken y la NEI también se aprecia en la obra de Coase, para quien el Estado es fundamental en la delimitación inicial de los derechos de propiedad (1960, p. 98). Además, puede intervenir de forma directa en el uso de los factores de producción, utilizando métodos autoritarios e imponiendo reglas mediante decisiones administrativas (ibíd., p. 100). Y como se sabe, en su artículo "El problema del costo social" (1960), Coase alteró los estándares de la intervención pública, un área en la que Coase y Eucken comparten puntos comunes.

E1 "mundo sin costos" del Teorema de Coase explica cuán eficaz puede ser el mercado en la resolución de las externalidades, con derechos de propiedad bien definidos y en ausencia de costos de transacción. Esto no significa que el papel del Estado no sea relevante, 
sino que en ciertas condiciones "ideales" puede ser irrelevante. Esta conclusión es la clave de la crítica de Coase al modelo de Welfare economics de Pigou (1934), por el carácter "antisocial" de la prohibición/ autorización y una intervención sin límites ${ }^{12}$. Si los tribunales definen los derechos iniciales y las partes afectadas negocian, la intervención y la aplicación de impuestos no tienen cabida. No niega la intervención; es más, en ciertas condiciones, el Estado y las instituciones ejercen un papel determinante porque su acción afecta los resultados económicos ${ }^{13}$. Un "Estado no siempre necesario", como corrector de externalidades, indica un claro sesgo liberal en las ideas de Coase.

Este rechazo a la interferencia directa del Estado en los asuntos económicos es compartido por Eucken, quien fue contrario a todo influjo de la Escuela de Cambridge, donde Keynes y Pigou dominaban el campo económico en los años treinta. En unas de sus referencias a Keynes sobre el problema de la ordenación del sistema económico, quien defiende la creación de "corporaciones semiautomáticas" en el marco del Estado, Eucken califica sus ideas como "medievales" y afirma:

causa extrañeza que Keynes se atreva a proponer tales formas de ordenación, en las cuales la ciencia sabe hace mucho tiempo que el proceso económico solo alcanza un equilibrio lábil y tiende al desequilibrio. La experiencia lo ha confirmado repetidas veces (Eucken, 1950c, 325).

Y se advierte una crítica velada al británico cuando en tono irónico dice que:

según la opinión dominante [...] la competencia se convierte en una forma anticuada de ordenación que, si antes quizá fue utilizable, hoy está superada. Para la ordenación de la economía son necesarios trusts, konzerns y cárteles, intervención estatal, corporaciones públicas, política de plena ocupación y planificación central (Eucken, 1950a, 41).

Para Eucken, la teoría y la política keynesiana de pleno empleo intentaban mantener en funcionamiento un aparato rígido, a pesar de las variaciones de la demanda, que no se adaptaba al funcionamiento real de la economía ${ }^{14}$.

Por su parte, Williamson (2000) profundiza y subraya aún más el papel de las instituciones, a las que clasifica en categorías que requieren cuatro niveles de análisis social: instituciones informales, reglas formales del juego, estructuras de gobierno (governance), y sistema

${ }^{12}$ Sobre este tema, ver Lottieri (2010).

${ }^{13}$ Sobre esta interpretación del teorema de Coase, ver San Emeterio (2006, p. 82).

${ }^{14}$ Para más detalles, ver Eucken (1950a, pp. 38-39). 
de asignación y ajustes de precios. Las similitudes con Eucken son evidentes: las "instituciones o estructuras de gobernanza" de Williamson son tres de los principios constituyentes de Eucken: derechos de propiedad, libertad de contrato y responsabilidad social.

\section{EL MONOPOLIO COMO ENEMIGO COMÚN}

Una de las principales preocupaciones de los autores ordoliberales es la de las implicaciones políticas de la concentración del poder económico, un antecedente del enfoque institucional de los mercados.

La obra de Eucken analiza los efectos nocivos de la concentración de las estructuras económicas recurriendo a la evidencia práctica; muestra las consecuencias de la concentración empresarial desde la época del laissez-faire, pasando por la Rusia de 1928 hasta la Alemania de 1936 en adelante, con la instauración de sistemas económicos de dirección centralizada: “Tan pronto como existieron grupos de poder se puso de manifiesto un círculo vicioso. Los grupos de poder consiguieron influencia político-económica y político-jurídica" (Eucken, 1950b, p. 183), ya que:

Los grupos económicamente poderosos están interesados en borrar la diferencia entre competencia y monopolio. Con ello se disimula la eficacia de los monopolios y pueden enmascararse los problemas especiales jurídicos y constitucional-económicos, planteados por la existencia de grupos particulares dotados de poder (Eucken, 1947, p. 145).

Sobre este punto, no parece muy distinto el razonamiento de North, que señala cierta preocupación por las posibles "presiones" de los grupos de interés en su análisis del papel del Estado.

Las instituciones no son creadas por la fuerza ni para ser eficientes socialmente; más bien estas instituciones, o cuando menos las reglas formales, son hechas para servir los intereses de quienes tiene el poder de negociación para crear nuevas normas (North, 1990a, p. 29).

Eucken reconoce que con la adopción de las modernas técnicas de producción la competencia se robusteció; aunque al mismo tiempo surgió una "inclinación a la formación de monopolio" cada vez mayor, asó como "Un imponente conjunto de medidas estatales y privadas [que] tratan de debilitar o de eliminar, en la economía moderna, la tendencia a la forma de mercado de competencia perfecta, que surge de la técnica" (Eucken, 1950a, p. 40-41).

La obra de Eucken surgió en una época en que los gobiernos sucumbían a los grupos de presión y adoptaban medidas que limitaban y restringían la competencia, de ahí que él y los demás autores de 
su corriente no cesaran de defender que el mejor orden económico posible es el "orden de la competencia" o Wettbewerbsordnung, cuya forma de mercado es la competencia perfecta.

En el orden de la competencia la política económica persigue dos objetivos: impedir comportamientos monopólicos y garantizar las libertades individuales. Aquí, el Estado tiene de nuevo un papel protagónico, pues en la concepción ordoliberal el orden de la competencia o sistema de economía de mercado no es un "orden natural" sin intervención estatal, sino muy al contrario. Por ello, frene a la dicotomía entre laissez-faire y economías de dirección centralizada Eucken sentencia: "La cuestión de una mayor o menor actividad del Estado en esencia está superada. Se trata no de un problema cuantitativo, sino cualitativo" (Eucken, 1950c, p. 337). Y especifica claramente lo que en su opinión debían ser las principales acciones del Estado, dejando el resto a las empresas y economías de consumo que deben planificarse y actuar libremente:

E1 Estado ha de negociar tratados de comercio, trazar un orden monetario suficiente, elaborar un derecho de patentes y contratos. En estas cuestiones ha de adoptar decisiones de carácter general sobre el orden político-económico, coordinando de modo racional las diferentes partes de la política económica (ibíd.).

Este último es un nuevo elemento común con la NEI, pues ambas corrientes consideran necesaria la intervención del Estado. Para la NEI, el Estado surge como una autoridad coercitiva que puede "forzar" el crecimiento económico, sobre todo a niveles crecientes de complejidad social. Como North puso de manifiesto en su obra, la historia muestra que la solución coercitiva en muchos casos ha sido claramente antieconómica, pero aun así es necesaria una entidad tercera que haga cumplir los contratos, cuando las negociaciones se realizan en un contexto más complicado y extenso, de intercambio impersonal no repetitivo, marcado por la incertidumbre, los costos de transacción positivos y la información incompleta:

Aunque puede haber crecimiento económico a corto plazo con un régimen autocrático, el crecimiento económico a largo plazo entraña el desarrollo de un Estado de derecho (North, 1994a, pp. 776-777).

Como hemos destacado, las reglas políticas están entrelazadas con las reglas económicas, lo que puede alterar la asignación inicial de los derechos de propiedad. North reconoce que el Estado también quiere maximizar sus ingresos y asegurar la permanencia de sus gobernantes; puede no ser imparcial, tener costos propios que limitan su acción y tamaño y enfrentar cambios históricos y tecnológicos: 
E1 cumplimiento obligatorio por una tercera parte significa una fuerza coercitiva capaz de monitorear derechos de propiedad y hacer cumplir contratos, pero de momento nadie sabe cómo crear tal identidad [...] si el Estado posee la fuerza coercitiva, entonces quienes rijan al Estado usarán esa fuerza en su propio interés, a expensas del resto de la sociedad (North, 1990a, pp. 82-83).

Igual que Eucken, North es consciente del poder que se arroga el Estado y del peligro que puede acarrear cuando los gobernantes usan ese poder en su propio beneficio. Su preocupación refuerza aún más el papel de las instituciones, en cuanto lleva a preguntar cómo se crean limitaciones institucionales eficientes que enmarquen la acción de las autoridades gubernamentales.

Aquí hay una divergencia analítica entre ambas escuelas. Si bien ambas reconocen la necesidad de la acción del Estado para resolver la problemática anticompetitiva de los mercados, Eucken señala claramente la función que debe cumplir el Estado para eliminar las prácticas monopólicas o la formación de cárteles, mientras que en North el análisis del Estado es mucho más teórico. Aborda su origen como institución y su potencial creativo y destructivo (puede alentar el crecimiento o ser responsable del estancamiento), pero no concreta su prescripción de política. No obstante, ambos concuerdan en el peligro de que los grupos de interés que controlan el Estado restrinjan la competencia (Eucken) o lleven al estancamiento económico a largo plazo (North).

Debemos recordar que el análisis institucional del ordoliberalismo es más político que teórico. No aborda la esencia económica de la institución, su origen y desarrollo. Para Eucken, como para sus colegas de Friburgo, las instituciones ya existen y su tema de estudio es cómo deben funcionar para conseguir un marco adecuado.

Por último hacemos una breve alusión a la actitud de Ronald Coase con respecto a los monopolios. En su obra más significativa no rechaza en forma específica los monopolios, pero esto no significa que no fuera contrario a ellos. De hecho, cuando se trasladó a Chicago, enseñó Derecho y Política de la Competencia (Antitrust en terminología anglosajona) (Klein, 2013, p. 305). De sus indicaciones se puede deducir que se dedicó a estudiar la organización dentro de la empresa competitiva para huir de la economía anti-monopolio que dominaba la organización industrial en los años treinta. No obstante, no dejó de adherirse a las lecciones de su maestro Arnold Plant quien le enseñó "que los gobiernos sirven a menudo a intereses especiales, promueven el monopolio antes que la competencia, y comúnmente imponen reglamentos que empeoran las cosas" (Coase, 1996a, p. 53). 
Es más ponderada la actitud de Williamson, quien desde la óptica de los costos de transacción señala la eficacia de los procesos de integración vertical, que al eliminar los inconvenientes que pueden surgir de la intermediación de proveedores externos, por ejemplo, reducen los costos de transacción. De allí la benevolencia que pide, en términos de regulación, hacia las fusiones empresariales cuando permiten economizar costos (Williamson, 1968).

\section{MULTIDISCIPLINARIEDAD}

La defensa de la comunión entre la economía y las demás dimensiones sociales es característica del institucionalismo así como de la corriente ordoliberal, que trata las cuestiones político-legales y político-económicas de manera conjunta, pues supone la interdependencia entre el orden económico y los restantes órdenes de la vida (Lebensordnungen). Esta visión multidisciplinaria de la economía como ciencia social es otro elemento común entre el ordoliberalismo y la NEI, pues ambas corrientes hacen hincapié en la colaboración entre concepciones teóricas y planteamientos prácticos de disciplinas como la historia, la estadística o las matemáticas.

El talante multidisciplinario de la escuela de Friburgo se hace evidente cuando se observa la formación de sus pioneros-economistas y juristas-y queda patente en la declaración de intenciones del primer número de Ordnung der Wirtschaft, de 1936, titulado "Nuestra tarea", en la que se señala que su principal objetivo es tratar de manera conjunta todas las cuestiones político-jurídicas y político-económicas. Tarea para la cual era fundamental la colaboración entre derecho y economía (Vanberg, 2004).

Esta ligazón entre las cuestiones económicas y legales es patente en el diseño de la constitución económica elaborada por Eucken, que combina principios netamente económicos con cuestiones legales y que defiende como elemento clave para el diseño de la Ordnungspolitik y la consecución de un orden económico adecuado:

Aquí y en todas las ramas de la política económica debiera estar presente al dictarse cada medida, el principio fundamental de la constitución jurídico-económica (Eucken, 1950c, p. 336).

Debemos tener en cuenta, además, que Eucken siempre tuvo en cuenta el contexto histórico, como resultado de la influencia de la escuela histórica alemana durante sus primeros años de formación en la Universidad de Bonn. Así como sus consideraciones cuando valora los efectos de las medidas de política económica, que expone en forma 
en sus disquisiciones sobre la necesidad de distinguir entre "principio" y "momento" de las circunstancias históricas: "En los distintos países el orden de la competencia toma realidad según la especial situación natural e histórica" (Eucken, 1950c, p. 328). Los órdenes político y económico quedan, entonces, estrechamente relacionados, pues una vez se toma una decisión de política económica, toda ley o nueva medida de política económica deberá valorarse en términos de su efecto sobre la estructura del mercado (Oswalt, 1994, p. 41).

Cabría preguntar aquí cuál es la posición de la Economía con respecto al Derecho o al pensamiento jurídico. A este respecto Eucken es concreto y tajante:

Solo con base en el orden económico pueden comprenderse importantes partes del Derecho vigente en sus interrelaciones, en especial cuando este orden se creó sistemáticamente y de acuerdo con ciertos principios (Eucken, 1947, p. 321).

A este respecto, en el análisis de North también intervienen factores vinculados al devenir del ser humano y de las sociedades: los procesos mentales y cognitivos y el aprendizaje (North, 2000). Estos aportes concuerdan con la relevancia de las cuestiones sociológicas, antropológicas y culturales que Williamson (2000) destaca en su trabajo sobre los niveles de análisis social.

En conjunto, los factores humanos, temporales y culturales, y la dimensión histórica del cambio, hacen posible que surja un tipo de instituciones y no otro, y que el crecimiento y el estancamiento económicos sean resultados alcanzables, pero basados en decisiones no siempre universales; lo que constituye "la teoría dinámica de cambio social" (North, 1990a, pp. 18-20). La NEI ha ido adoptando un perfil multidisciplinario, y sus aportes nutren ramas del conocimiento que tratan fenómenos de diferente naturaleza. Este es un nexo con la preocupación ordoliberal por el trasfondo social de un sistema económico y su visión multidisciplinaria del proceso económico.

Edificar una teoría de las instituciones sobre el fundamento de elecciones individuales es un paso hacia la reconciliación de diferencias entre las ciencias económicas y las otras ciencias sociales (North, 1990a, p. 16).

La economía de las estructuras de gobierno de Williamson también abre una brecha a la necesaria convergencia interdisciplinaria para comprender las relaciones contractuales:

Interdisciplinariedad de las ciencias sociales: este es el último de los cuatro conceptos básicos que asocio a la economía de las estructuras de 
gobierno $^{15}$. [...] Teoría de la organización y aspectos del derecho (sobre todo del derecho contractual), ambos tienen un peso importante en la economía de las estructuras de gobierno (Williamson, 2005, p. 9).

No menos contundentes son las palabras de Coase en su discurso de apertura en la conferencia anual de la International Society for New International Economics de 1999, que invitan a poner fin a la preocupación por el "imperialismo" de la economía, y a entablar una cooperación fructífera entre las ciencias sociales:

La introducción del análisis económico en las demás ciencias sociales ha sido definido imperialismo económico. Nosotros estamos volcados en un proyecto totalmente distinto: recurrir a la ayuda de otros científicos sociales para ser capaces de entender mejor cómo funciona el sistema económico (Coase, 1999)

Así pues, la necesidad de interrelacionar las diferentes disciplinas sociales para un mejor diseño del "orden de mercado" o "instituciones" y, por ende, mejores resultados, es otro nuevo paralelismo entre ordoliberalismo y NEI; y es una cuestión nada baladí en la que han hecho hincapié autores de ambas corrientes:

Los economistas [...] pueden estudiar otros sistemas sociales, como el legal o el político, no con el fin de contribuir al derecho o a las ciencias políticas sino porque es necesario si quieren entender el sistema económico en sí mismo. Muchos economistas se han dado cuenta de que hay partes de los otros sistemas tan entremezclados con el sistema económico que forman parte tanto del sistema económico como del sociológico, el político o el social (Coase, 2009, p. 58).

Todo trabajo sobre las cosas tiene que dirigirse a dominarlas. Con no menos frecuencia resuena el grito de que historiadores y teóricos deberían colaborar en la Economía, y que nada habría más perjudicial que la lucha entre ambos (Eucken, 1947, p. 38).

\section{LA EMPRESA COMO INSTITUCIÓN}

Quizás en contra de lo que cabría esperar, la concepción del funcionamiento de la economía de la escuela de Friburgo no termina con el análisis del papel del Estado; también tiene en cuenta otras estructuras institucionales. Las palabras de Eucken no dejan lugar a dudas: "Empresas y economías domésticas son miembros del orden económico total, y los procesos en unas y otras, procesos parciales del proceso social de conjunto" (ibíd., p. 322).

15 Esos cuatro conceptos básicos Williamson son: estructuras de gobierno, costos de transacción, adaptación e interdisciplinariedad de las ciencias sociales. 
Ello subyace en la delimitación de la labor del Estado en el orden de la competencia elaborada por Eucken, la cual hace hincapié en que la dirección del proceso económico compete a las empresas y a las economías de consumo que planifican y actúan libremente (Eucken, 1950c, p. 327). Al tiempo que conviven con el Estado como artífice del marco institucional en el que "se mueven cotidianamente" (Eucken, 1950 b, p. 179). "La totalidad del proceso económico cotidiano tiene lugar en millones de economías de consumo y empresas, pero forma al mismo tiempo una unidad" (ibíd., p. 180). Esto coincide con la concepción de la NEI, tal como la expone Coase:

Para tener un sistema económico eficiente es necesario no solo tener mercados sino también áreas de planificación apropiadas dentro de las organizaciones, y [...] lo que surge de esa mezcla es resultado de la competencia (Coase, 2009, p. 18).

Schmidtchen argumenta que si bien los economistas alemanes de la época no se preguntaron por qué existían las empresas, sí se preguntaron por qué todas las actividades económicas no son coordinadas por una dirección central, en otras palabras, por qué existen los mercados (Schmidtchen, 1984, p. 65-66). Su razón de ser era "coordinar los planes y decisiones de las diversas empresas y economías de consumo"(Eucken, 1950c, p. 327), pues son unidades independientes en su constitución y funciones, que hacen más por llevar el proceso económico al equilibrio que una administración económica centralizada (Schmidtchen, 1984, p. 66); aunque forman parte de un sistema económico único coordinado por el Estado. Las empresas y economías domésticas son estructuras que "independizan a los individuos del mercado y en tiempos difíciles dan una cierta seguridad”, pero a las que en ningún caso se les daría la función de dirigir el proceso económico. Solo se deben concebir como una forma complementaria de ordenación. La que impone su sello al orden económico es la competencia perfecta (Eucken, 1950c, p. 328).

Así, en la concepción del funcionamiento del orden económico de Eucken hay una convivencia de empresas y economías domésticas, pero "no [se les] puede encomendar por completo [...] la creación de las formas, del marco y, en general, del orden económico" (Eucken, $1950 b$, p. 184). De modo que la "empresa" sería una institución que organiza y planifica, y que complementa al mercado en su labor de asignar recursos. Una visión similar a la de la NEI, para la cual además del Estado, la empresa es una alternativa a los mecanismos de mercado.

Esta idea concuerda con los planteamientos de Alchian y Demsetz, pioneros en el campo de la organización industrial con enfoque institucional, quienes señalan: 
En contraste con los mercados o las ciudades, que pueden considerarse lugares de intercambio públicos o sin propietario, la empresa puede contemplarse como un mercado de propiedad privada; si esto es así, podemos considerar a la empresa y al mercado ordinario como dos clases de mercados en competencia entre sí, competencia entre mercados de propiedad privada y mercados públicos o comunitarios (Alchian y Demsetz, 1972, pp. 169-170).

En otro artículo fundamental, "La naturaleza de la empresa” (1937), Coase define la empresa como una opción organizativa que sustituye la lógica de intercambio del mercado, cuando las transacciones a través de esta organización tienen costos menores de los que tendrían a través del mercado; considerando costos de transacción positivos (Coase, 1937, pp. 561-562).

En su investigación, Williamson retoma la preocupación de Coase por los factores que determinan cuándo una empresa produce un bien o servicio para sus propias necesidades y cuándo es más eficiente externalizarlo. Los costos de transacción vuelven a ser el determinante principal de la actividad económica; en Williamson se reafirma la importancia de las instituciones y del marco institucional, la empresa asciende al rango de estructura de gobierno (jerárquica y organizativa) y deja de ser función de la producción $(2005$, p. 9).

De modo que las instituciones y estructuras de gobierno económico contribuyen al establecimiento de un "orden” y la organización interna de la empresa es clave en la contratación, lo que concuerda con la concepción teórica del escenario ideal de Eucken. Para él, cada empresa y economía de consumo planifica y actúa libremente en el marco diseñado por el Estado que nunca intervendrá, salvo que los planes o decisiones de las empresas o economías de consumo no estén coordinadas. Solo en ese caso "se precisan medidas de política económica especiales" (Eucken, 1950c, pp. 327-328). ¿De qué dependerá, entonces, que se opte por una u otra forma de organización? Del cumplimiento de los principios constituyentes que configuran la constitución económica, en concreto del principio de libertad de contratación, puesto que es una "precondición para la realización de la competencia", que deberá ser protegido por el Estado para que no derive en monopolios. La autogestión de empresas y economías domésticas se permite siempre y cuando no tenga consecuencias negativas para el orden del mercado.

\section{CONCLUSIONES}

En las páginas anteriores identificamos importantes puntos en común -y alguna discrepancia- entre el ordoliberalismo de Walter 
Eucken y los pioneros de la NEI. Aquí exponemos las principales conclusiones.

1. Hay puntos en común entre la NEI y el ordoliberalismo en los principios constituyentes de la constitución económica enunciados por Eucken.

2. Los principios constituyentes de la Ordnungspolitik buscan construir un marco institucional estable que reduzca los costos de transacción, donde el Estado establece las reglas. En esta concepción de la libre competencia y en el diseño de este marco institucional hay convergencia con los autores institucionalistas.

3. Ambas corrientes subrayan la necesidad de un marco adecuado para el desarrollo de la competencia sin dirección ni planificación del Estado. En este sentido, comparten el rechazo a las políticas económicas de corte keynesiano y pigouviano.

4. Con respecto al Estado, ambas son conscientes del peligro de que los gobernantes sean presos de los grupos de interés, y restrinjan la competencia (Eucken) o el crecimiento (North).

5.Existen algunas discrepancias que no se deben ignorar: el planteamiento de la NEI es un análisis teórico -como sus tesis sobre los costos de transacción- inexistente en la obra de Eucken. También se observan en el papel del Estado, sobre todo en la obra de North, quien considera necesaria una teoría política del Estado, el cual es fundamental así como su capacidad para influir en el proceso económico. North reconoce que el análisis institucional no es completo y satisfactorio, pero es sin duda pertinente. Eucken no elabora una teoría económica del Estado, pero analiza cómo puede influir el Estado. tal como lo conocemos, en el proceso económico.

6. También discrepan en su papel como institución, pues para la NEI tiene una capacidad de actuar más reducida que para la corriente ordoliberal, aunque se aprecian similitudes en la visión de la empresa como institución alternativa al Estado de autores institucionales posteriores.

7. Eucken y los autores institucionalistas retoman la concepción multidisciplinaria de la economía que existía en la obra de Adam Smith y que se perdió en la formulación de David Ricardo.

8. Por último, este artículo sugiere una estrecha relación entre el ordoliberalismo y el neoliberalismo alemán. Un tema de investigación que cabría desarrollar en futuros trabajos.

\section{REFERENCIAS BIBLIOGRÁFICAS}

Alchian, A. y Demsetz, H. (1972). Production, information cost and economic organization. American Economic Review, 62(5), 777-795. 
Cesarotto, S., Stirati, A. (2011). Germany and the European global crises. Quaderni del Dipartimento di Economia Politica, 607, 1-37.

Coase, R. H. (1937). The nature of firm. Economica, 4(16), 386-405.

Coase, R. H. (1960). The problem of social cost. Journal of Law $\Xi^{\circ}$ Economics, 3, 1-44.

Coase, R. H. (1996a). La naturaleza de empresa: origen. En O. Williamson y S. Winter (comps.), La naturaleza de la empresa: orígenes, evolución y desarrollo (pp. 49-66). México DF: Fondo de Cultura Económica.

Coase, R. H. (1996b). La naturaleza de empresa: significado. En O. Williamson y S. Winter (comps.), La Naturaleza de la empresa: orígenes, evolución y desarrollo (pp. 67-84). México DF: Fondo de Cultura Económica.

Coase, R. H. (1999). Discurso de apertura en la conferencia anual de la International Society for New Institucional Economics. Newsletter of the International Society for New Institutional Economics, 2(2), [http:// www.isnie.org].

Coase, R. H. (2009). Ensayos sobre economía y economistas. Madrid: Marcial Pons

Dullien, S. y Guérot, U. (2012). The long shadow of Ordoliberalism: Germany's approach to the euro crisis. European Council on Foreing Relations Policy Brief.

Eucken, W. (1947). Cuestiones fundamentales de la economía politica. Madrid: Revista de Occidente.

Eucken, W. (1950a). Política económica del "laissez-faire”, economía planificada y orden de la competencia. Arbor, enero, 33-43.

Eucken, W. (1950b). Política económica del laissez-faire, economía planificada y orden de la competencia. Arbor, febrero, 179-190.

Eucken, W. (1950c). Política económica del laissez-faire, economía planificada y orden de la competencia. Arbor, marzo, 323-337.

Eucken, W. (2017). Principios de politica económica. Pamplona: Editorial Aranzadi.

García E., S. (2018). Contribución de la escuela de Friburgo al pensamiento económico europeo. Reflexiones en torno a la obra básica de Walter Eucken Principios de politica económica, Conferencias y trabajos de investigación 392, Universidad de Alcalá.

Hutchison, T. W. (1979). Notes on the effects of economic ideas on policy: The example of the German social market economy. Bd. 135, H. 3. Currency and Economic Reform: West Germany after World War II: A Symposium, 426-441.

Klein, D. B. (2013), Ronald Coase. Ideological profiles of the economics laureates. Economic Journal Watch, 10(3), 299-307.

Lottieri, C. (2010). Ronald Coase e l'analisi economica del Diritto. Osservazioni critiche. Ircocervo, 2, 1-25.

Mirowski, P. (2009). Defining Neoliberalism. En P. Mirowski y D. Plehwe (eds.), The road from Mont Pelèrin (pp. 417-455). Cambridge: Harvard University Press.

North, D. C. (1990a). Institutions, institutional change and economic performance. Cambridge: Cambridge University Press. 
North, D. C. (1990b). A transaction cost theory of politics. Journal of Theoretical Politics, 2(4), 355-367.

North, D. C. (1994a). La evolución de las economías en el transcurso del tiempo. Revista de Historia Económica/Journal of Iberian and Latin American Economic History, 12(3), 763-778.

North, D. C. (1994b). Estructura y cambio en la historia económica. Madrid: Alianza Editorial.

North, D. C. (2000). La evolución histórica de las formas de gobierno. Revista de Economia Institucional, 2(2), 133-148.

Oswalt-E., I. (1994). Freedom and economic power: Neglected aspects of Walter Eucken's Work. Journal of Economics Studies, 21(4), 38-45.

Pigou, A., C. (1934). The economics of welfare. Londres: Macmillan.

Plehwe, D. (2009). Introduction. En P. Mirowski y D. Plehwe (eds.), The road from Mont Pèlerin (pp. 98-138). Cambridge, Mass.: Harvard University Press.

Ptak, R. (2009). Neoliberalism in Germany. En P. Mirowski y D. Plehwe (eds.), The road from Mont Pelerin (pp. 98-138). Cambridge, Mass.: Harvard University Press.

Richter, R. (2000). Institutional thought in Germany, International Society for New Institutional Economics (ISNIE). Tubinga, 22-24

Richter, R. (2010). German 'Ordnungstheorie' from the perspective of the New Institutional Economics, [http://ssrn.com/abstract=1815563].

Sally, R. (2012). L'ordoliberalismo e il mercato sociale. Il liberalismo che salvó la Germania, Instituto Bruno Leoni occasional paper 89.

San Emeterio, N. (2006). Nueva economía institucional. Madrid: Editorial Síntesis.

Schnyder, G. y Siems, M. (2013). The Ordoliberal variety of Neoliberalism. En S. Konzelmann y M. Fovargue-D. (eds.), Banking systems in the crisis: The faces of liberal capitalism (pp. 250-268). Abingdon: Routledge.

Simons, Henry C. (1948). Economic policy for a free society. University of Chicago Press, Chicago, Ill.

Vanberg, V. J. (2004). The Freiburg School: Walter Eucken and Ordoliberalism, Freiburg discussion papers on Constitutional Economics 04/11. Friburgo: Walter Eucken Institut.

Vanberg, V. J. (2006). Constitutional political economy, Freiburg Discussion papers on Constitutional Economics. Friburgo: Walter Eucken Institut.

Van Sutum, U. Böhm, T. et al. (2011). Walter Eucken's principles of economic policy today, CAWM discussion paper 49. Münster: CAWM.

Vatiero, M. (2010). The Ordoliberal notion of market power: An institutionalist reassessment. European Competition Journal, 6(3), 689-707.

Velarde F., J. (1998). Discurso con motivo de su investidura como Doctor Honoris Causa. Universidad de Alicante, 5 de noviembre.

Williamson, O. (1968). Economies as an antitrust defense: The welfare tradeoffs. American Economic Review, 58(1), 18-36.

Williamson, O. y Winter, S. (comps.). (1996). La naturaleza de la empresa: orígenes, evolución y desarrollo. México DF: Fondo de Cultura Económica. 
Williamson, O. (1999). Public vs. private bureaucracies: A transaction cost economic perspective. Journal of Law, Economics and Organization, 15(1), 307-342.

Williamson, O. (2000). The New Institutional Economics: Taking stock, looking ahead. Journal of Economic Literature, 28, 595-613.

Williamson, O. (2005). Economics of governance. American Economic Review, 95(2), 1-18.

Williamson, O. (2007). An interview with Oliver Williamson. Journal of Institutional Economics, 3(3), 373-386. 